\title{
Endonasal endoscopic dacryocystorhinostomy in the paediatric population*
}

Carla C. Moreira, Isabel M. Correia, Inês S. Cunha, Herédio Sousa, Ezequiel Barros

Otolaryngology Department, Centro Hospitalar de Lisboa Central, Lisbon, Portugal
Rhinology Online, Vol 2: 99 - 102, 2019

http://doi.org/10.4193/RHINOL/19.007

*Received for publication:

February 13, 2019

Accepted: July 8, 2019

Published: July 20, 2019

\section{Abstract}

Background: Congenital nasolacrimal duct obstruction is frequent and paediatric endonasal endoscopic dacryocystorhinostomy (DCR) is increasingly used after conservative treatment failure.

Methodology: Retrospective noncomparative case series study was conducted from January 2007 to August 2017. Patients under 18 years old with nasolacrimal system obstruction who underwent endoscopic DCR were studied. All children were referred to our otorhinolaryngology department in a tertiary referral paediatric hospital. Population characteristics, presentation symptoms, success rate and predictive factors for failure were analysed.

Results: 30 children were identified. Ages varied from 2 to 13 years old. Simultaneous bilateral surgery was performed in 5/30 $(16,7 \%)$ children. Silicone stents were used in $93 \%$ of interventions with a mean time to removal of 9,6 weeks. Persistent epiphora was found in $43 \%$ of children and recurrent dacryocystitis in $57 \%$. Success rate for primary DCR was $83,3 \%$. Revision surgery was performed in $16,7 \%$ of cases. Minor complications rate was 13,3\%. The presence of concomitant chronic nasal infections pointed for surgery failure reaching statistical significant value $(p=0.0456)$.

Conclusions: Paediatric endonasal endoscopic DCR seems to be an effective, safe and minimally invasive technique for the treatment of mechanical nasolacrimal system obstruction.

Key words: congenital nasolacrimal duct obstruction (CNLDO), endonasal dacryocystorhinostomy, paediatric dacryocystorhinostomy

\section{Introduction}

Congenital nasolacrimal duct obstruction is frequent and affect nearly $20 \%$ of infants during the first year of life manifesting itself by the appearance of epiphora ${ }^{(1)}$. This phenomenon occurs due to an imperforate membrane at the valve of Hasner. However, almost $96 \%{ }^{(2)}$ of all CNLDO will resolve spontaneously. Consequently, CNLDO is the most common indication for dacryocystorhinostomy in the paediatric group ${ }^{(2)}$, although adquired causes such as ethmoidal sinusitis or maxillofacial trauma may also cause nasolacrimal pathway disturbances and should be investigated. Despite being considered a safe procedure, DCR is indicated only when conservative management fails. Conservative therapy consists in medical therapy (including compression or massage of the nasolacrimal sac, topical antibiotics and irrigation), probing(s) and intubation ${ }^{(3)}$. Most patients respond to this conservative approach. In refractory cases of sachal and post sachal obstructions, recurrent or chronic dacryocystitis, cases with associated mucocele and/or adquired nasolacrimal duct obstruction, external DCR has been historically the way of management. Nowadays, endoscopic surgery has been taking 
the lead on this matter and although data in the paediatric group are not so common as in adults, endoscopic endonasal DCR is being increasingly used and offers advantages, especially in children, over external DCR with the same success rates reported in the literature. Advantages include: absence of external facial scar; direct observation and possible simultaneous correction of sinonasal pathologies; preservation of pump function (orbicularis oculi muscle, medial palpebral ligaments); less trauma to medial canthal, orbital tissue and nasal mucosa; less bleeding during surgery; less time-consuming; and shorter postoperative course $\mathrm{e}^{(1)}$.

In this line of thought we purpose to report our outcomes of paediatric patients with lacrimal system obstruction who underwent endonasal endoscopic DCR in our paediatric tertiary care hospital, analyse our success rate and evaluate possible predictive factors for failure.

\section{Materials and Methods}

\section{Study design}

We conducted a retrospective noncomparative case series study from January 2007 to August 2017.

\section{Patients}

Patients under 18 years old with nasolacrimal system obstruction who underwent endoscopic DCR were studied ( $N=30)$. All children were referred to our otorhinolaryngology department in a tertiary referral paediatric hospital in Lisbon, Portugal.

\section{Investigational methods}

Data were collected from medical records and via interviews with the parents. Population characteristics, presentation symptoms, success rate and predictive factors for failure were analysed.

\section{Surgical technique used}

All children underwent endoscopic endonasal dacryocystorhinostomy under general anesthesia. Before the surgery, the nasal mucosa was decongested by leaving pledgets soaked in fenilefrin chloride $(0.025 \%)$ in the nasal cavity for $10 \mathrm{~min}$. A 4.0-mm scope was used during the procedure. Elevation and excision of a posteriorly based mucoperiosteal flap centered on the lacrimal eminence was first performed using a stryker ${ }^{\circledR}$ colorado needle and the underlying bone was exposed. Osteotomy of the anterior lacrimal crest/lacrimal bone was done using a diamond burr exposing the medial surface of the lacrimal sac. After identifying the lacrimal sac, an incision of the medial surface of the lacrimal sac was performed with a sickle knife, creating a fistula from the sac to the nasal cavity. Dilation of puncta and insertion of bicanalicular nasal silicone stents was done after and silicone stents were grasped with a punch forceps and pulled out of the nasal cavity. The silicone stents were tied and left in the nasal cavity in $93 \%$ of cases. In children were silicone stents were not placed this was due to superior punctum agenesia or presence of concomitant acute rhinosinusitis at time of surgery. Nasal packing was performed in cases with persistent and significant hemorrhage, and the packing material was removed within 24 h. All of the patients received prophylactic antibiotic (amoxicillin/clavulanic acid according to the children weight) for 7 days. The length of the hospital stay was 1 day.

Patients were advised to do nasal irrigations with saline (3-4 times a day) for at least 2 weeks and debridement of crusts was performed weekly in cooperative children for a month. Patients were examined 1 week after the surgery and at monthly intervals for 6 months. Our follow-up was in mean 26.4 months (range from 3 to 144 months). At each follow-up visit parents were asked about the recurrence of epiphora and/ or eye discharge. The silicone stents were removed in mean at 9.6 weeks (range from 4 to 20 weeks) after the operation. From those $93 \%$ of patients with silicone stents, $50 \%$ of them required removal under sedation on the operatory room because of lack of cooperation under local anaesthesia in office. The patency of the lacrimonasal fistula was tested after the stents were removed by applying pressure to the punctum and by endoscopically observing the flow of lacrimal fluid through the nasal cavity. The procedure was considered to be successful when there was resolution of epiphora and/or dacryocystitis by clinical evaluation and parent's history.

\section{Statistical analysis}

The resultant data were statistically analyzed by applying Chisquare test, using the SPSS (version 16.0) software. Statistical significance was accepted at $\mathrm{p}$ values of $<0.05$.

\section{Results}

We performed a total of 42 endonasal endoscopic DCRs in children at our institution from January 2007 to August 2017 in a population of 30 patients.

There were 18 (60\%) boys and 12 (40\%) girls in our study. Patient's age ranged between 2 and 13 years, with a mean age of 6.5 years old (Figure 1).

The indications for endoscopic dacryocystorhinostomy included congenital nasolacrimal duct obstruction, subacute dacryocysititis and obstructive pathologies that were unresponsive to conservative treatment. The ophthalmic examination including an assessment of the eyelids and puncta was conducted by an ophthalmologist. All children had failed previously massage, syringing, probing and/or intubation performed by an ophthalmologist. The diagnosis of nasolacrimal duct obstruction was based on the presence of epiphora and/or eye discharge obtain by meticulous physical exam, the clinical history obtained from parents and in $66,7 \%$ of cases dacryocystography was performed to evaluate the level of obstruction. Paranasal sinus computed 


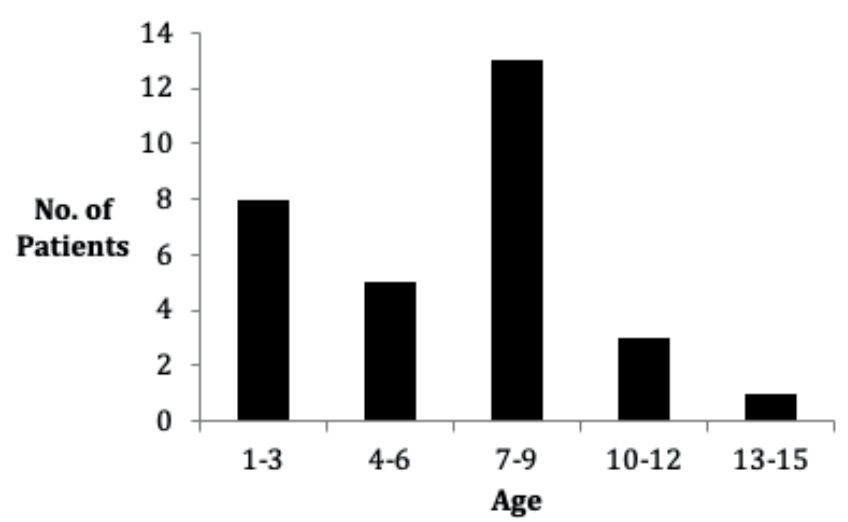

Figure 1. Age distribution of the patients.
Table 1. Minor complications reported.

\begin{tabular}{|lcl|}
\hline Minor complications & No. of cases (\%) & \multicolumn{1}{c|}{ Comments } \\
\hline $\begin{array}{l}\text { Granuloma around } \\
\text { the stoma }\end{array}$ & $1(3,3 \%)$ & $\begin{array}{l}\text { Extracted under local } \\
\text { anesthesia }\end{array}$ \\
$\begin{array}{l}\text { Synechia (between } \\
\text { medial turbinate, } \\
\text { septum and lateral } \\
\text { nasal wall) }\end{array}$ & $2(6,7 \%)$ & $\begin{array}{l}\text { (1) Corrected during } \\
\text { revision surgery } \\
(1) \text { Corrected during } \\
\text { stent removal }\end{array}$ \\
\hline $\begin{array}{l}\text { Migration of stent to } \\
\text { lacrimal sac }\end{array}$ & $1(3,3 \%)$ & $\begin{array}{l}\text { Repositioned under } \\
\text { unconscious sedation }\end{array}$ \\
\hline
\end{tabular}

tomography was only performed in $23,3 \%$ of patients, including those with craniofacial dysmorphy and/or concomitant sinonasal pathology.

Congenital NLDO was the indication for surgery in all children. In 17 (57\%) children we found epiphora with recurrent dacryocystitis and in 13 (43\%) persistent epiphora.

Bilateral endonasal endoscopic DCR was performed in 5 patients, with a total of 35 primary DCRs in our group. From our population ( $\mathrm{N}=30), 5$ cases needed a revision surgery and 2 cases underwent a second revision DCR.

We found that $14(46,7 \%)$ patients had comorbidities, including concomitant sinonasal pathology was present in 12 (40\%) children, cranial dysmorphy in $1(3,3 \%)$ and cleft lip and palate in 1 (3,3\%) patient.

Regarding concomitant sinonasal pathology, the most frequent comorbidity found in our series, we found $7 / 12$ children with adenoid hypertrophy/chronic adenoiditis, 2/12 with nasal septum deviation, $2 / 12$ with allergic rhinitis and $1 / 12$ with chronic ethmoid and maxillary rhinosinusitis without nasal polyps. As previously mentioned, the mean time from surgery to removal of the silicone stents was 9.6 weeks (range from 4 to 20 weeks) and the mean follow-up period was 26.4 months (range from 3 to 144 months). No major complications were encountered and postoperative course was uneventful in $83,3 \%$ of cases. Minor complications rate was $13,3 \%$. A granuloma around the stoma developed in 1 (3,3\%) patient, synechiae between the medial turbinate, the septum and the lateral nasal wall was found in $2(6,7 \%)$ patients and migration of stent to the lacrimal sac occurred in 1 (3,3\%) patient (Table 1).

The overall success rate for primary endonasal endoscopic DCR was $83,3 \%$ (35/42) and in children under 4 years old of $87,5 \%$ (7/8).

Revision surgery was performed in $16,7 \%$ (7/42) of cases. The reclosure of the opening between the lacrimal sac and the nasal cavity with recurrence of symptoms lead to revision surgery in 5 cases and in 2 cases a second revision surgery was needed until complete resolution of symptoms was achieved.
When we looked for possible factors for failure, and applying Chi-square test we found that there was statistically significant difference between the group of patients that needed revision surgery and those with success on primary DCR regarding the presence of concomitant chronic nasal infections (adenoiditis/ rhinosinusitis/allergic rhinitis) (33,3\% vs. 5,6\%; $p=0.0456)$. For this reason, adenoidectomy or minimal functional endoscopic sinus surgery was also performed during revision endonasal endoscopic DCR in 4 failure cases.

\section{Discussion}

Congenital NLDO is the most common indication for dacryocystorhinostomy in the pediatric age group ${ }^{(3)}$. Congenital NLDO generally resolves spontaneously or responds well to conservative treatments including nasolacrimal massage, administration of antibiotics, balloon dacryoplasty and silicone intubation ${ }^{(2)}$. Endonasal endoscopic dacryocystorhinostomy is an effective procedure for treatment of mechanical nasolacrimal system obstruction unresponsive to previous conservative treatment. This procedure is a safe and minimally invasive technique, which provides excellent results with reduced morbidity. Kominek et al. ${ }^{(3)}$ reported a $92.2 \%$ success rate. In another study, Knijnik ${ }^{(4)}$ reported that $77.8 \%$ of primary endonasal endoscopic dacryocystorhinostomy procedures were successful. A total of $94.4 \%$ fulfilled the success criteria in another study ${ }^{(5)}$. In our study, our success rate was $83.3 \%$, which is comparable with the rates reported in the literature. When we undergo pediatric endonasal endoscopic dacryocystorhinostomy we have to take into account some particularities. Children have small nasal cavities and some of them present with septal deviations, which makes this a more difficult procedure ${ }^{(6)}$. More bleeding after mucosal incision ${ }^{(7)}$ is also expected in this group of patients, as well as difficult post-surgical hygiene ${ }^{(8)}$. Endoscopic dacryocystorhinostomy can lead to several complications, including orbital fat herniation ${ }^{(3)}$, orbital emphysema ${ }^{(5)}$, conjunctival fistula ${ }^{(9)}$, cicatrization complications (granuloma, synechiae) ${ }^{(2,3)}$ and profuse hemorrhage ${ }^{(5)}$. In our series, no major complications were reported. A granuloma 
developed around the ostium in 1 patient, synechiae between the medial turbinate, the septum and the lateral nasal wall was found in 2 and migration of stent to the lacrimal sac occurred in 1 patient. There is a large discussion about possible factors for failure in this group of patients. Among them we can find, craniofacial malformations ${ }^{(10)}$, premature removal of silicone stents ${ }^{(3,7,11)}$, cicatrization complications such as granuloma formation or synechiae ${ }^{(11)}$, or chronic nasal infections (adenoiditis/ rhinosinusitis/allergic rhinitis) ${ }^{(10)}$. In our study we found that there was a statistically significant difference between the group of patients that needed revision surgery and those with success on primary DCR regarding the presence of concomitant chronic nasal infections ( $p=0.0456$ ). Endonasal endoscopic dacryocystorhinostomy is an effective procedure which provides excellent results with reduced morbidity.

\section{Conclusion}

In our study, the success rate (83.3\%) is comparable to other described in the literature and similar to that described for adults.

\section{Acknowledgement}

Not applicable.

\section{Authorship contribution}

CCM, IMC, ISC, HS, EB: Substantial contributions to the conception, design of the work; to the acquisition, analysis, and interpretation of data for the work; drafting the work and revising it critically for important intellectual content; final approval of the version to be published; agreement to be accountable for all aspects of the work in ensuring that questions related to the accuracy or integrity of any part of the work are appropriately investigated and resolved.

\section{Conflict of interest}

The authors have no conflicts of interest to declare.

\section{Ethics approval and consent to participate}

The study was approved by the local ethics committee.

\section{Consent for publication}

Not applicable.

\section{Availability of data and materials}

All data generated or analysed during this study are included in this published article.

\section{Funding}

Not applicable.

\section{References}

1. Gioacchini FM, Alicandri-Ciufelli M, Kaleci S, Re M. The outcomes of endoscopic dacryocystorhinostomy in children: A systematic review. Int. J. of Pediatr. Otorhinolaryngol. 2015;79:947-952

2. Celenk F, Mumbuc S, Durucu C, et al. Pediatric endonasal endoscopic dacryocystorhinostomy. Int. J. Pediatr. Otorhinolaryngol. 2013;77:1259-1262.

3. Komínek P, Cervenka S, Matousek P, Pniak T, Zeleník K. Primary pediatric endonasa dacryocystorhinostomy - a review of 58 procedures. Int. J. Pediatr. Otorhinolaryngol. 2010;74:661-664.

4. Knijnik D. Endonasal dacryocystorhinostomy in children. Braz. J. Otorhinolaryngol. 2005;71:726-728.

5. Gupta AK, Bansal S. Primary endoscopic dacryocystorhinostomy in childrenanalysis of 18 patients. Int. J. Pediatr. Otorhinolaryngol. 2006;70:1213-1217.
6. Leibovitch I, Selva D, Tsirbas A, Greenrod A, Pater J, Wormmald PJ. Paediatric endoscopic endonasal dacryocystorhinostomy in congenital nasolacrimal duct obstruction. Graefes Arch. Clin. Exp. Ophthalmol. 2006;244:1250-1254.

7. Eloy P, Leruth E, Cailliau A, Collet S, Bertrand B, Rombaux P. Pediatric endonasal endoscopic dacryocystorhinostomy. Int. J. Pediatr. Otorhinolaryngol. 2009;73:867-871.

8. de Souza CE, Nisar J, de Souza RA. Pediatric endoscopic dacryocystorhinostomy. Otolaryngol. Head Neck Surg. 2012;147:335337.

9. Woog JJ, Kennedy RH, Custer PL, Kaltreider SA, Meyer DR, Camara JG. Endonasal dacryocystorhinostomy: a report by the American Academy of Ophthalmology. Ophthalmology 2001;108:2369-2377.

10. Jones DT, Fajardo NF, Petersen RA VanderVeen DK. Pediatric endoscopic dacryocystorhinostomy failures: who and why? Laryngoscope 2007;117:323-327

11. Cunningham MJ. Endoscopic management of pediatric nasolacrimal anomalies. Otolaryngol. Clin. North Am. 2006;39:10591074

Carla Moreira

Otorhinolaryngology Department

Centro Hospitalar e Universitário de

Lisboa Central

Lisbon,

Portugal

Tel: +35-196-173 7169

E-mail: carlafilipamoreira@gmail.com

ISSN: 2589-5613 / @2019 The Author(s). This work is licensed under a Creative Commons Attribution 4.0 International License. The images or other third party material in this article are included in the article's Creative Commons license, unless indicated otherwise in the credit line; if the material is not included under the Creative Commons license, users will need to obtain permission from the license holder to reproduce the material. To view a copy of this license, visit http://creativecommons.org/ licenses/by/4.0/ 